\title{
ATIVIDADES DE ELABORAÇÃO CONCEITUAL POR ESTUDANTES NA SALA DE AULA DE FÍSICA NA EJA
}

\author{
Erico Tadeu Fraga Freitas* \\ Orlando Aguiar Jr. **
}

RESUMO: Neste trabalho analisa-se a atividade de elaboração conceitual por jovens e adultos no contexto da sala de aula de Física, na aprendizagem da primeira lei de Newton. O material empírico analisado consiste das produções escritas dos alunos, nas quais argumentam sobre a possibilidade de movimento da Terra valendo-se dos conceitos de inércia e movimento relativo. A análise, inspirada na Filosofia da Linguagem de Bakhtin, se volta para os conteúdos e modos de dizer dos estudantes, buscando neles examinar os diálogos entre suas próprias palavras e as "palavras alheias" da ciência escolar. Indicamos cuidados metodológicos na seleção e análise do texto, para o qual foram usados alguns dos modos de relação entre a palavra alheia e o sujeito falante: "o assentimento" e "os entrelaçamentos", a partir da noção de "discurso citado" e "construção híbrida". Os resultados obtidos indicam uma maior relação de assentimento dos estudantes ao discurso da ciência escolar.

Palavras-chave: Formação de Conceitos. Apropriação. Análise do Discurso. Bakhtin. EJA.

\section{STUDENTS' CONCEPTUAL ACTIVITIES IN ADULT EDUCATION IN THE PHYSICS CLASSROOM}

ABSTRACT: In this paper we shall analyze a conceptual activity elaborated by adults in a physics classroom context, related to the Newton's First Law of Motion. The data comes from writing activities carried out by the students, in which they debate about the possibility of the Earth motion using concepts of inertia and relative movement. The analysis, founded in Bakhtin's Philosophy of Language, is focused on the contents and compositional structure of the students utterances, in order to examine the dialogs between their own words and the "alien words" of school science. We show some methodological procedures related to the selection and analysis of such texts. For the analysis we use some kind of relationships between alien words and the subject: 'agreement' and 'interlacing', drawn on the notions of 'quoted discourse' and 'hybrid construction'. The results indicate a larger 'agreement' position of the adult students with the school science discourse.

Keywords: Conceptual Development. Appropriation. Discourse Analysis. Bakhtin. Adult Education. 


\section{INTRODUÇÃO}

Neste trabalho examinamos a construção de significados por estudantes jovens e adultos na sala de aula de Física a partir de suas produções escritas, forjadas no contexto de uma atividade avaliativa, nas quais os estudantes argumentam sobre a possibilidade de movimento da Terra. Nosso interesse é investigar a elaboração conceitual dos estudantes por meio das relações que estabelecem entre o conhecimento científico escolar e seu conhecimento cotidiano, fundado na experiência de vida que configura a cultura desses educandos. A perspectiva teórico-metodológica que adotamos neste trabalho leva em conta como os diferentes fatores da experiência pessoal, da linguagem e da socialização se inter-relacionam no processo de aprendizagem em ciências (DRIVER et al., 1994/1999; MORTIMER, 2000; MORTIMER; SCOTT, 2002, 2003; VILLANI; NASCIMENTO, 2003), particularmente em se tratando de jovens e adultos (COELHO; EITERER, 2006; FREIRE, 1992).

O problema das relações que os estudantes estabelecem com o conhecimento científico escolar vem sendo examinado, no campo da educação em ciências, a partir de diferentes abordagens teórico-metodológicas. Parece-nos promissora e esclarecedora a perspectiva de análise das produções discursivas (oral e/ou escrita) dos estudantes em situação escolar inspirada na filosofia da linguagem de M. Bakhtin.

Ao examinarmos as atividades discursivas dos estudantes na sala de aula, os modos de falar dos estudantes estão relacionados às "palavras alheias" (BAKHTIN, 1997). Em seus enunciados ecoam os enunciados do professor e a "vOz" da ciência escolar. Esses ecos podem revelar alguns modos de relação entre suas próprias palavras e as "palavras alheias": o assentimento, os entrelaçamentos e os questionamentos (FONTANA, 1996).

Os modos de relação que os estudantes estabelecem com o discurso alheio se dão numa relação de alternância entre um discurso que cumpre uma função unívoca - cujos códigos do transmissor e do receptor coincidem quase completamente -, e um discurso que cumpre uma função dialógica - que procura gerar novos significados (LOTMAN, 1988 apud MORTIMER; MACHADO, 1997).

Há uma tensão entre essas duas funções do discurso científico escolar, identificadas por Mortimer e Scott (2003) enquanto diferentes abordagens comunicativas dos professores de ciências em sala de aula. Do nosso ponto de vista, essa tensão pode ser também identificada nas produções, intervenções e intenções dos estudantes em sala de aula (AGUIAR; MORTIMER, 2006; AGUIAR; MENDONÇA; SILVA, 2007; MENDONÇA; AGUIAR; SILVA, 2008; SILVA; AGUIAR, 2008). De um lado, os estudantes buscam um compartilhamento de significados com o professor e a visão canônica da ciência. Esse compartilhamento da "voz" da ciência escolar com a mediação do professor possibilita aos alunos apropriarem-se dos modos de dizer da ciência, 
que eles ainda não dominam de forma autônoma. De outro lado, os estudantes constroem relações entre a visão da ciência escolar e outros modos de falar e pensar o mundo, fundados na experiência cotidiana. Essas marcas pessoais nos enunciados dos alunos, por meio de contra-palavras ressignificando o dizer alheio, revela seu esforço para se apropriarem e internalizarem o discurso da ciência escolar.

Essa tensão no discurso dos estudantes pode revelar aspectos importantes em seus processos de conceituação. Revelam, ainda, as tensões existentes entre, de um lado, as diferentes tradições culturais nas quais os estudantes da EJA estão inseridos e, de outro, a cultura escolar. Parece-nos, portanto, promissor estudar as relações que os estudantes estabelecem com o conhecimento científico escolar nas atividades que realizam em sala de aula.

\section{OBJETIVOS}

Neste trabalho analisamos a produção escrita de alguns estudantes de ensino médio, da modalidade de Educação de Jovens e Adultos (EJA), forjadas no contexto de uma atividade avaliativa. A avaliação foi realizada após uma sequência de ensino sobre inércia e relatividade dos movimentos desenvolvida a partir de uma problematização histórica das possibilidades de movimento da Terra. Nosso objetivo é investigar os modos de relação que os estudantes estabelecem com o conhecimento científico escolar, por meio de uma análise das produções discursivas desses educandos em suas produções escritas. Para tanto, direcionaremos nosso olhar para os modos de dizer dos estudantes, buscando neles examinar os diálogos entre/com as "palavras alheias" e suas próprias palavras (FONTANA, 1996).

\section{METODOLOGIA}

Para analisar as produções discursivas dos estudantes, é preciso antes considerar o contexto educacional em que estão inseridos os sujeitos da pesquisa, a proposta de ensino e situações de produção que desencadearam a produção escrita dos estudantes. Tais cuidados decorrem do princípio bakhtiniano de que todo enunciado é um elo em uma cadeia de comunicação humana - ou seja, é uma resposta a outros enunciados que o antecederam e antecipa, de certo modo, outras respostas dos interlocutores. Além disso, Bakhtin nos alerta para o fato de que todo discurso é configurado pelas circunstâncias e pelo lugar social em que é produzido, buscando uma adequação ao gênero próprio de um dado contexto de interação social.

A seleção da produção escrita dos estudantes decorre do nosso interesse de pesquisa. Para a análise do material empírico, selecionamos um número reduzido de textos que fossem representativos do conjunto de textos 
produzidos na turma, e que indicassem um maior envolvimento dos estudantes com a tarefa proposta - proposição de texto argumentativo sobre a possibilidade de movimento da Terra. Para os demais textos marcamos apenas a presença, ou não, de cada uma das quatro categorias descritas na seção anterior.

\subsection{0 contexto educacional da pesquisa}

A base de dados desta pesquisa foi organizada a partir das produções escritas de alguns estudantes de EJA (ensino médio), em uma avaliação após uma sequência de ensino sobre a primeira lei de Newton, em março de 2007. O contexto dessa pesquisa é uma sala de aula de Física de uma escola da Fundação de Ensino de Contagem (FUNEC), em Contagem/MG.

\subsubsection{Os jovens-adultos da pesquisa}

A turma, na qual foi desenvolvida a sequência, tinha 41 alunos, com idades variando entre 25 e 75 anos. Para nossas análises neste trabalho, selecionamos as produções escritas de cinco $^{1}$ estudantes, sendo duas do sexo feminino, e três do sexo masculino. Identificamos esses estudantes com nomes fictícios: Pedro, Tiago, João, Marta e Raquel.

Cada um desses jovens-adultos traz consigo um conjunto de experiências, vivências sociais e projetos de vida muito distintos, e dentro da diversidade presente no grupo de alunos deste trabalho, é possível identificar algumas características que lhes conferem certa homogeneidade. Segundo Oliveira (1999/2004), todos eles chegam à sala de aula na condição "nãocrianças", excluídos do processo de escolarização no tempo "normal" e membros de determinados grupos culturais.

No que diz respeito aos grupos culturais a que pertencem esses sujeitos, esses têm sido descritos como bastante homogêneos, compostos primordialmente por cidadãos de baixa renda, migrantes que chegaram às grandes metrópoles provenientes de áreas rurais empobrecidas, filhos de trabalhadores rurais não-qualificados e com baixo nível de instrução escolar (muito frequentemente analfabetos), com passagem curta e não sistemática pela escola e inseridos no mercado de trabalho em ocupações urbanas não qualificadas, após experiência como trabalhadores rurais na infância e na juventude. (OLIVEIRA, 2004, p. 220).

Um ponto a ser considerado é que os processos de construção de conhecimento e aprendizagem dos adultos são muito menos explorados em trabalhos interessados na questão da aprendizagem e do desenvolvimento cognitivo, do que aqueles referentes às crianças e adolescentes. Entretanto, é importante considerar a vida adulta como etapa substantiva do desenvolvimento. Segundo Oliveira (2004), no que diz respeito ao funcionamento intelectual do adulto, as pessoas mantêm um bom nível de competência cognitiva até uma idade avançada. Os adultos trazem consigo uma história mais longa de experiências, conhecimentos acumulados e reflexões sobre o mundo e sobre si mesmos, e isso faz com que tragam diferentes habilidades e dificuldades (em 
relação à criança e ao adolescente), e uma capacidade diferenciada de refletirem sobre o conhecimento e sobre seus próprios processos de aprendizagem.

\subsubsection{0 professor-pesquisador}

Este trabalho é resultado de um processo de ação-reflexão-ação. O primeiro autor deste trabalho é protagonista das situações de ensino descritas neste artigo. Reconhecemos os desafios que tal tarefa nos coloca. Entretanto, nos detemos apenas nas produções escritas dos estudantes como base de dados desta pesquisa, e focamos nossa análise nesse material.

As aulas que descrevemos a seguir não foram gravadas, tampouco foram feitos registros escritos sobre as aulas. A sequência de ensino é descrita a partir dos relatos do professor das situações de ensino em sala de aula.

\subsection{0 contexto escolar e a sequência de ensino}

O curso de Ensino Médio da EJA na FUNEC tem uma estrutura modular. São três módulos e cada um é composto por três disciplinas, em média. No Módulo $\mathrm{III}^{2}$ os estudantes são matriculados em Física, Química e Língua Inglesa; e as disciplinas não se repetem por módulo. Ao final de três semestres consecutivos, o aluno termina o Ensino Médio nessa modalidade da educação básica. As aulas de Física acontecem duas vezes por semana (dois encontros); cada encontro equivale a cinco aulas (com duração aproximada de 45 minutos cada) e são dedicados apenas ao estudo de uma disciplina. Portanto, são dez aulas semanais de Física.

A seguir descrevemos a sequência de ensino sobre a Lei da Inércia, que foi desenvolvida num total de três encontros no final de março de 2007.

\subsubsection{0 primeiro encontro}

A sequência de ensino se inicia na segunda metade do primeiro encontro. O professor inicia dirigindo uma questão à turma: É a Terra que gira em torno do Sol, ou é o Sol que gira em torno da Terra? Vários estudantes respondem ao mesmo tempo, dizendo que a Terra é que gira em torno do Sol. Em seguida o professor afirma que ninguém sente a Terra se mover, e todos os dias o que se vê é o Sol nascer de um lado do céu e se pôr do outro lado. Então, o professor traz para a cena da sala de aula alguns elementos procurando problematizar essa questão.

O professor conduz uma exposição e conta uma breve história sobre a Revolução Copernicana. Comenta sobre a visão de universo na Grécia Antiga; que durante muitos anos acreditou-se que o Sol e os outros planetas é que giravam ao redor da Terra, estando ela absolutamente parada no centro do Universo. Resumidamente, o professor explica que, entre os séculos XV e XVI, o astrônomo Nicolau Copérnico sugeriu que o Sol era o centro do universo e que a Terra girava ao seu redor, pensamento que contradizia a crença na época; e disse aos alunos que Galileu, anos depois, viria defender a teoria de Copérnico. 
O professor propõe à turma que admitam que o Sol gire ao redor da Terra, e enuncia para seus alunos quais eram os questionamentos que os opositores de Galileu lhe faziam, em decorrência de tal hipótese. Nesse contexto, desenvolve problematizações sobre a queda dos objetos e sua trajetória em uma Terra em movimento. Ao serem informados das velocidades do movimento de translação e rotação de um ponto na superfície do equador terrestre, os estudantes se mostram ansiosos em saber por que não percebemos esse movimento. Alguns alunos sugerem ser devido à gravidade. O professor não comenta essa e outras respostas, mas diz que juntos iriam responder essas questões ao longo das aulas seguintes, e que pensar nessas questões seria importante para admitir a possibilidade de movimento da Terra.

\subsubsection{0 segundo encontro}

No segundo encontro o professor inicia a aula trazendo novamente as questões apresentadas na aula anterior; e apresenta uma atividade sobre a primeira Lei de Newton. Essa atividade consiste de um texto extraído das Leituras de Física, do GREF (1998, p. 59, 60; Anexo 1), acompanhado de algumas questões e exercícios (Anexo 1).

A sala de aula é dividida em pequenos grupos e uma cópia da atividade é entregue para cada aluno. Realiza-se uma leitura conjunta do texto didático e em seguida o professor pede aos grupos que respondam as questões e exercícios propostos. Alguns alunos se oferecem para realizar a leitura em voz alta para toda a turma, enquanto os demais acompanham. O professor interrompe a leitura em alguns momentos, ora para esclarecer aos alunos alguns aspectos que considera importantes para a compreensão do conteúdo, ora fazendo perguntas aos alunos para verificar sua compreensão do texto.

À medida que a leitura é realizada, o professor dá ênfase aos exemplos descritos no texto. Os contextos de movimentos no interior de uma cabine fechada de um avião em movimento são explorados em detalhe com os estudantes. Esse exemplo é estendido para outras situações mais próximas da realidade dos alunos, como o movimento de um carro, ou do metrô. Tais contextos são, então, utilizados por analogia ao do movimento de pessoas e objetos na superfície da Terra.

A turma continua a leitura conjunta do texto, e no quinto parágrafo o professor chama a atenção dos estudantes para a importância de se escolher um referencial a partir do qual possa ser analisado o movimento de certo objeto.

Após a leitura do texto, o professor pede aos grupos que respondam as questões propostas nessa atividade. Durante o desenvolvimento da atividade, o professor atende aos grupos em suas dúvidas sobre as questões.

A atividade de leitura conjunta e as interrupções realizadas pelo professor para esclarecer aspectos relevantes dos conceitos expostos no texto parece ser fundamental, pois abre um espaço para os alunos trazerem algo de seu conhecimento para o contexto da sala de aula, socializando suas experiências e 
as interpretações que atribuem às ideias científicas veiculadas pelo texto. Em outros momentos as intervenções do professor buscam aproximar o horizonte conceitual dos alunos e o horizonte conceitual do texto didático, conferindo maior legibilidade ao texto.

Nas trocas que se estabelecem em sala de aula o professor procura interagir com os alunos, ora de forma dialógica, abrindo o discurso para as contribuições e pontos de vista dos estudantes, ora realizando um discurso de autoridade, centrado nas ideias-chave da ciência escolar. Essas intervenções ocorrem tanto em momentos de exposição dos conteúdos como em outros momentos em que os alunos trabalham em pequenos grupos, ao responderem as questões e exercícios propostos.

\subsubsection{0 terceiro encontro}

No terceiro encontro o professor tenta resgatar os conceitos estudados na aula anterior, numa revisão sobre a Lei da Inércia e suas implicações no tratamento do problema do movimento da Terra. Pretendendo fechar essa sequência de ensino, o professor propõe uma atividade 3 (Anexo 2), para ser realizada em pequenos grupos. A sala de aula é organizada em grupos de cinco alunos, em média; os alunos iniciam a atividade que envolve extrapolação e aplicação dos conceitos de inércia e relatividade de movimentos em outros contextos.

$\mathrm{Na}$ segunda parte da atividade, o professor realiza uma leitura do texto "Preconceito muito pra frente", de Millôr Fernandes ${ }^{4}$ (Anexo 2). Nesse texto, o cronista expõe sua opinião argumentando que a Terra está absolutamente parada, pois sobre ela caminhamos sem sentirmos o menor movimento. Millôr critica as pessoas que aceitam, sem pensar, as teorias dos cientistas, de cujas 'provas' a maioria delas não conhece e nem sabem dizer quais são.

Os alunos são convidados a escrever uma carta em resposta a Millôr Fernandes, tentando convencê-lo de que é possível pensar que a Terra se move. Os grupos começam, então, a realizar a atividade proposta, e o professor passa pelos grupos discutindo com os alunos os conceitos de inércia, sistema de referência e movimento relativo, procurando fornecer ajuda e suporte na realização dessa nova tarefa. Além disso, o professor incentiva os alunos a articular os conceitos aprendidos utilizando-os como argumentos para defender posições.

\section{BASE DE DADOS: AS PRODUCְ̃̃ES ESCRITAS DOS ALUNOS}

As produções escritas que constituem a base de dados deste trabalho foram elaboradas pelos estudantes durante uma avaliação final da primeira etapa do semestre letivo, três semanas após o término da sequência de ensino. A avaliação foi realizada individualmente e sem consulta. A primeira questão da avaliação final (Anexo 3), semelhante à atividade da produção das cartas descrita 
anteriormente, solicitava ao estudante que produzisse um pequeno texto argumentando a favor da hipótese de Galileu de que a Terra se move. A seguir, estão reproduzidos cinco textos elaborados pelos alunos, durante a realização da avaliação.

Estas redações constituem a base de dados deste trabalho, e é neste material que detemos a análise sobre os modos de dizer dos estudantes e como se relacionam com a palavra alheia, ou seja, o discurso científico escolar e os modos de falar do professor. Os textos dos estudantes foram reproduzidos integralmente sem qualquer correção ortográfica e gramatical. Os grifos que aparecem nestes textos foram feitos pelos próprios estudantes.

\section{Texto 1 - Aluno: Pedro}

O fato de não sentirmos o movimento da Terra não significa que a $\mathbf{1}$

Terra se encontre parada. Se tivermos a bordo de uma aeronave 2 em vôo, se não houvesse a turbulência do vôo qualquer que $\mathbf{3}$ estivesse em seu interior pensaria que não estaria em movimento. 4 pelo exemplo acima podemos entender que o "sentir" não pode por $\mathbf{5}$ se so determinar se estamos ou não em movimento $\quad \mathbf{6}$

A Terra se move com velocidade constante, nesse movimento não 7 existe o atrito e a segunda lei da inercia todo corpo em movimento $\mathbf{8}$ tende a continuar e todo corpo em repouso tende a permanecer em 9 repouso. $\quad 10$ E relação ao movimento da Terra devemos entende-lo não pelo $\mathbf{1 1}$ movimento normal, mas pelo movimento relativo, pois se $\mathbf{1 2}$ analisarmos pelo normal podemos incorrer em erro. 13 Em conclusão entendemos que a hipótese de galileu atende a todo 14 esbaldo da ciência física

\section{Texto 2 - Aluna: Marta}

Depois de estudarmos as idéias de Galileu, eu concordo com ele e $\mathbf{1}$ também acho que a terra se move. dependendo do ponto referencial! 2 do ponto de vista em que estamos vendo, se estivermos por cima da terra não $\quad 3$ vamos sentir os seus movimentos, ao passo que se ficarmos fora 4 dela, saberemos que ela se movimenta, é como se estivéssemos $\mathbf{5}$ dentro de um carro, se olharmos para quem está sentado ao nosso $\mathbf{6}$ lado, vamos ver a pessoa parada, se estivermos do lado de fora e 7 $\begin{array}{ll}\text { este carro estiver numa velocidade constante, vamos ver que o carro } & \mathbf{8}\end{array}$ está em movimento, é o movimento relativo isto é depende do ponto $\mathbf{9}$ de vista de quem está vendo, apesar da lei da inercia que diz que $\mathbf{1 0}$ todo objeto que está em repouso tende a permanecer em repouso e $\mathbf{1 1}$ todo objeto que está em movimento tende a permanecer em 12 movimento, a não ser que exista uma força maior que o atraia eu 13 acho que é isso que acontece com a terra, ela tem uma força que a 14 coloca em movimento. 


\section{Texto 3 - Aluna: Raquel}

Até então acreditava-se que a terra não movia-se, mas ao contrario 1 que se falava ela se movimenta, não percebemos por ela ter uma 2 velocidade constante é como estivessemos no carro em movimento, $\mathbf{3}$ nós não ia sentir seu movimento, isto iria depender do ponto de vista 4 em que se está, fora do carro veriamos que o carro é que está em $\mathbf{5}$ movimento, dentro dele estariamos em movimento, mas se o carro $\mathbf{6}$ parasse de repente ia nos jogar para frente, isto depende, $\mathrm{O} 7$ movimento relativo depende do ponto de vista, $\quad \mathbf{8}$ Isto tudo é que a lei da Inércia, pode ter movimento mas não $\mathbf{9}$ setimos, caso tenha alguma trepidação algo que possa tirar a terá $\mathbf{1 0}$ do seu eixo nós sentiriamos

\section{Texto 4 - Aluno: Tiago}

Argumentando a favor de Galileu, nos podemos dizer que quando 1 estamos parado em algum lugar ou dentro de um lugar fechado, 2 temos a impressão de estarmos parado em relação aquele lugar, mas $\mathbf{3}$ quando estamos em um carro ou ônibus vemos que as coisas as 4 paisagens estão passando por-nós então podemos dizer que estamos em $\mathbf{5}$ relação ao ambiente fora do ônibus podemos dizer que estamos em $\mathbf{6}$ movimento, Então podemos dizer que estamos em 7 movimento ou parado depende do ponto de referência. E quanto a $\mathbf{8}$ terra podemos dizer que está em velocidade constante

\section{Texto 5 - Aluno: João}

A terra se move porque não podemos sentir o movimento relativo da $\mathbf{1}$ terra mais podemos observar entre o dia e a noite, também a 2 velocidade constante da terra somente e reparada do lado difora da $\mathbf{3}$ Terra. E a Lei da inércia não posso te dizer no momento nada sobre 4 ela pois esqueci, mas que a terra se move é verdade

\section{CATEGORIAS DE ANÁLISE}

Nesta seção descreveremos as categorias de análise para examinar cada uma das produções escritas dos estudantes, que constitui a base de dados deste trabalho. Procuramos caracterizar as estratégias enunciativas utilizadas pelos estudantes na produção de seus textos e baseamo-nos em Fontana (1996) para direcionar nosso olhar e análise para a diversidade dos modos de dizer dos alunos, buscando neles examinar as relações entre/com as "palavras alheias", por meio de alguns modos de relação entre a palavra alheia e o sujeito falante: $o$ assentimento, os entrelaçamentos, os questionamentos e a indiferença.

O assentimento (FONTANA, 1996), como modo de relação entre os modos de falar do aluno e a palavra alheia, é marcado nos enunciados dos alunos pela utilização do discurso do professor na sua integridade. Em algumas enunciações dos estudantes, veremos que estes utilizam em seus próprios 
enunciados exemplos didáticos que compõem o discurso do professor e do texto didático, sem entonações próprias nem marcas de individualização.

Os entrelaçamentos são marcados por um rompimento da homogeneidade entre seus modos de dizer e a voz alheia. Outra voz aparece incorporada ao enunciado do estudante; uma "própria-palavra" ressignificando o dizer do professor. Nesse caso, o discurso do outro não é citado na sua integridade, como uma estrutura compacta e fechada. A voz do outro (do professor e da ciência escolar) aparece diluída no discurso dos estudantes e estes a ressignificam em nível individual, para produzir suas asserções.

Os questionamentos caracterizam-se por uma "contra-palavra" que problematiza o discurso alheio. Essa problematização do dizer do outro (ainda que não conscientemente), aprofunda o espaço de discussão entre os dizeres alheios e as palavras interiores.

Do nosso ponto de vista, ainda acrescentamos uma quarta categoria: a indiferença. Nesse modo de relação, os modos de dizer do estudante revelam um desprendimento, um desinteresse frente ao discurso alheio da ciência escolar.

\section{AS ESTRATÉGIAS ENUNCIATIVAS DOS ESTUDANTES E SEQUÊNCIAS TEXTUAIS}

Em cada enunciado permeiam outras vozes e estas se apresentam enquanto ecos e/ou ressonância com os modos de dizer do sujeito falante. Bakhtin (1997) afirma que todo enunciado é um elo na cadeia da comunicação discursiva, e a alternância entre os sujeitos do discurso determinam os limites desses enunciados.

Os enunciados são fortemente marcados pelas condições institucionais e sociais de sua produção, o que implica o uso de gêneros de discurso socialmente estabelecidos. No caso que analisamos, os alunos procuram ajustar seus conteúdos temáticos e modos de dizer às circunstâncias de enunciação e em acordo com o gênero do discurso da ciência escolar.

Segundo Bakhtin (1997) cada enunciado é uma resposta a outro enunciado que o antecede, e essa atividade responsiva pode adquirir diferentes expressões. A expressão de um enunciado não é determinada apenas pelo objeto do discurso, mas também pelos enunciados do outro sobre o mesmo tema/objeto.

No Texto 1, o estudante Pedro inicia com uma reprodução fiel do discurso do professor e do livro didático ( $1^{\circ}$ parágrafo) para, em seguida $\left(2^{\circ}, 3^{\circ}\right.$ e $4^{\circ}$ parágrafos) introduzir vários outros elementos em diálogo com estes, de modo a ressignificar tal discurso em sua perspectiva. Assim, o assentimento vai dando lugar aos entrelaçamentos. O texto apresenta uma estrutura argumentativa (BRONCKART, 1999), conduzindo das premissas à conclusão.

A frase de abertura do texto (linhas 1 e 2) constitui uma premissa, uma vez que propõe uma constatação de partida, assentindo à voz da ciência escolar. Em seguida (linhas 2 a 4) há a apresentação de uma explicação por analogia que 
parece orientar para uma conclusão provável acerca da premissa inicial; aqui ecoa a voz do professor e do texto didático no enunciado do estudante, por meio da evocação de um exemplo didático veiculado pelo texto e reiterado pelo professor nas aulas. $\mathrm{Na}$ frase que finaliza o primeiro parágrafo (linhas 5 e 6) Pedro procura reiterar a premissa inicial. Nesse primeiro parágrafo predomina uma relação de assentimento do estudante em relação às palavras alheias, ou seja, ao discurso da ciência escolar.

Ao contrário disso, no segundo parágrafo, Pedro traz em seu texto suas próprias entonações e observamos um entrelaçamento entre a voz do estudante (seu horizonte cultural) e aquela da ciência escolar. Nesse trecho, Pedro constrói um argumento (TOULMIN, 2001) e inicia apresentando uma conclusão (linha 7), uma alegação que reproduz a voz alheia, e cujos méritos o estudante procurará estabelecer. A partir do final da linha 7 até a linha 10, uma "própria-palavra" ressignificando o dizer do professor marca a utilização da operação de análise do estudante a partir de outro critério: a exclusão de uma determinada situação (a inexistência do atrito) funciona com um dado ao qual o estudante recorre como fundamento para sua conclusão. Em seguida, ele apresenta uma garantia citando a lei da inércia, tentando explicitar uma relação entre o dado e a conclusão. Não há evidências que a "própria-palavra" que Pedro apresenta em seu enunciado entre as linhas 7 e 10 ("nesse movimento não existe o atrito") seja uma "própria-palavra". Talvez seja um entrelaçamento que o estudante faz com outro texto que não circulou em sala de aula.

Notamos entre as linhas 11 e 13, uma concepção espontânea do movimento absoluto. O "movimento normal" constitui-se numa essência do movimento do objeto (a Terra) (VILLANI; PACCA; HOUSOME, 1985). Para Pedro parece haver observadores privilegiados que têm condições de analisar, de forma coerente, o movimento próprio ou verdadeiro. Nesse trecho, Pedro ressignifica o conhecimento científico escolar à luz do conhecimento cotidiano por meio da ideia de movimento absoluto.

Os modos de dizer do Pedro, no Texto 1, não revelam marcas de entonação próprias. O estudante utiliza os verbos na primeira pessoa do plural (o plural majestático), o que também fica evidente na conclusão apresentada (linhas 14 e 15).

No Texto 2, Marta expressa seu enunciado por meio de uma sequência narrativa (BRONCKART, 1999). Seu texto é implicado e isso se mostra por meio do uso do pronome pessoal "eu”, o que evidencia marcas de entonação própria.

$\mathrm{Na}$ primeira frase (linhas 1 e 2) a estudante apresenta uma situação inicial de orientação. Ela apresenta um estado inicial de coisas se posicionando (pessoalmente) em relação ao problema de se pensar na possibilidade de movimento da Terra. O desenrolar de sua narrativa irá introduzir nesse estado uma perturbação (entre as linhas 2 e 5) que cria uma certa tensão sobre o sentir ou não sentir o movimento da Terra, a depender do referencial. Aqui há uma experiência de pensamento, o que evidencia uma operação, pela estudante, no mundo dos modelos. 
Ao final da linha 5, até a linha 10, Marta apresenta uma resolução à tensão criada no enunciado anterior, introduzindo acontecimentos desencadeados pela perturbação. A estudante apresenta um exemplo didático; e há predominância de seu assentimento em relação ao discurso da ciência escolar.

A partir da linha 10, os modos de falar de Marta revelam um entrelaçamento com o discurso do texto didático (GREF, 1998, p. 59; Anexo 1). Entre as linhas 10 e 12, a estudante apresenta uma objeção à lei da inércia e ressignifica o conhecimento científico escolar à luz de sua concepção espontânea (a partir do final da linha 12) sobre a existência de uma 'força capitalizadora' (VILLANI; PACCA, 1985) capaz de explicar a persistência do movimento da Terra (entre as linhas 14 e 15). Novamente a orientação (pessoal) da estudante em relação ao problema é marcada pelo uso do pronome na primeira pessoa do singular (linha 13).

No Texto 3, à semelhança do que é feito no Texto 2, a estudante Raquel expressa seus enunciados por meio de uma sequência narrativa. Ela inicia seu texto com um marcador temporal que remete à história contada pelo professor sobre o modelo geocêntrico. Em seguida a estudante faz uma frase declarativa (entre as linhas 1 e 2) que evidencia uma concepção realista do movimento da Terra, e como apontam Villani e Pacca (1985) como algo que tem existência em si mesmo. Esse trecho caracteriza uma situação inicial de exposição. De forma semelhante ao Texto 2, o estado de movimento da Terra é apresentado como fato. A partir da linha 2, a estudante apresenta uma complicação; ela parece querer criar uma perturbação ao dizer que não se percebe o movimento da Terra - "não percebemos". E, então, faz uma avaliação ao propor um comentário relativo a isso - "por ela ter uma velocidade constante", se valendo da voz da ciência escolar.

A partir da linha 3, até a linha 8, os modos de falar da estudante Raquel reproduzem a voz do professor e do texto didático (GREF, 1998, p. 59; Anexo1). Nesse trecho a estudante procura apresentar uma resolução por meio do exemplo didático para diminuir a tensão criada pela complicação. Observamos que os modos de dizer da estudante revelam novamente uma concepção espontânea sobre movimento (linhas 5 e 6 ). O movimento relativo é substituído por uma soma de movimentos absolutos (VILLANI; PACCA, 1985). Nesse trecho a estudante declara: “(...) fora do carro veríamos que o carro é que está em movimento, dentro dele estaríamos em movimento". Essa declaração evidencia que, para a estudante, a velocidade real é obtida da velocidade do objeto considerado (as pessoas dentro do carro), com a do objeto que o arrasta (o carro).

Ao final do Texto 3 (entre as linhas 9 e 11) aparecem nos modos de falar da estudante, outras vozes entrelaçadas à sua própria voz. Ela apresenta uma situação final procurando explicar o estado de movimento da Terra. Entre as linhas 10 e 11, a estudante entrelaça seus modos de dizer com o discurso do professor, por meio de uma analogia com um exemplo didático utilizado nas aulas.

No Texto 4, o estudante Tiago utiliza como expressão de seu enunciado, uma forma de organização da ordem do narrar (BRONCKART, 1999), em que 
os acontecimentos e ações são dispostos de forma linear e não registram qualquer processo de tensão. Bronckart (1999) chama essa forma de organização de script. O conteúdo temático do Texto 4 está organizado em uma ordem que reflete a cronologia dos acontecimentos narrados nos cinco primeiros parágrafos do texto didático (GREF, 1998, p. 59; Anexo 1).

Em todo o enunciado do estudante Tiago, seus modos de dizer revelam uma relação de total assentimento com a voz do professor (da linha 1 ao final da linha 3; da linha 7 ao final da linha 8), com a voz do texto didático (do final da linha 3 ao início da linha 7) e, portanto, com o discurso da ciência escolar (a partir do final linha 8). Percebe-se nesse texto que esse estudante apresenta dificuldades em lidar com a produção textual; há uma marca forte da oralidade. A conclusão que Tiago apresenta na última frase é descolada do texto.

O Texto 5 também é marcado pela oralidade. Nesse texto, João inicia assentindo à voz da ciência escolar ao admitir o estado de movimento da Terra. Em seguida (linha 2), ele tenta apresentar uma situação ("podemos observar entre o dia e a noite") que possa reforçar a ideia da Terra em movimento. Aqui, ecoa outra voz (não a do professor) no enunciado do estudante. Talvez um outro texto que não circulou em sala de aula.

A partir do final da linha 2 até o início da linha 4, o estudante assente à voz do professor. Em seguida, seus modos de dizer revelam uma relação de indiferença ao discurso alheio. Declaradamente, o enunciado de João entre as linhas 4 e 5 representa uma atividade responsiva que revelam um desprendimento em relação ao discurso da ciência escolar. Ao final, há um posicionamento em relação ao estado de movimento da Terra.

Os demais textos que compõem a base de dados deste trabalho foram analisados apenas com base nas categorias descritas na seção 2. A tabela a seguir representa a presença, ou não, desses modos de relação nos enunciados dos textos dos estudantes.

Tabela 1: Distribuição dos modos de relação entre as palavras alheias e as próprias palavras nos textos produzidos pelos estudantes

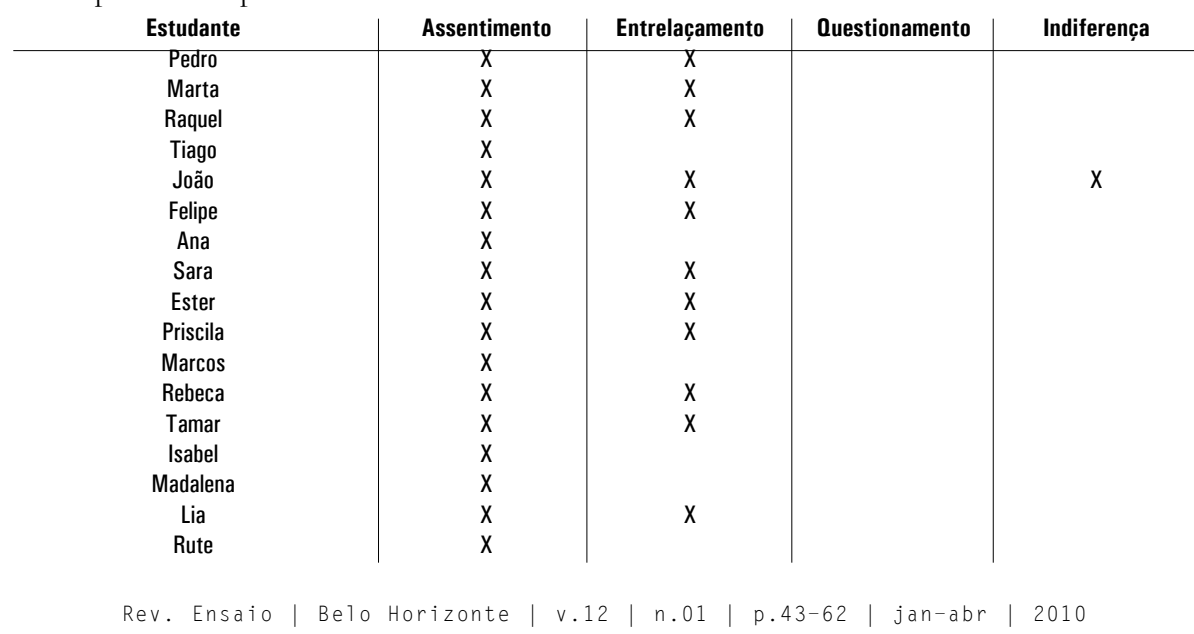




\section{CONSIDERAÇÕES FINAIS}

A formação de conceitos científicos pelos estudantes tem sido um dos temas de maior interesse da pesquisa em educação em ciências (LIMA; AGUIAR JR; MARTINS, 2005; MORTIMER; SCOTT, 2002; SILVA; AGUIAR JR, 2008). Entretanto, a pesquisa em educação e ciências, na modalidade de Educação de Jovens e Adultos é ainda incipiente. O presente trabalho é um ensaio inicial para uma pesquisa na qual investigamos o processo de elaboração conceitual por jovens e adultos nas atividades discursivas na sala de aula de Física.

Assumimos aqui, uma perspectiva que leva em conta como os vários fatores da experiência pessoal, da linguagem e da socialização se interrelacionam no processo de aprendizagem da ciência escolar (DRIVER et al., 1994/1999; MORTIMER; SCOTT, 2002). Compartilhamos da convicção pedagógica no campo da EJA a respeito da importância de levar em conta os conhecimentos construídos a partir da experiência vivida que configura a cultura do educando (COELHO; EITERER, 2006).

Nessa perspectiva, a aprendizagem das ciências é vista como construção social do conhecimento, e envolve a introdução em um mundo simbólico mediante o qual o indivíduo socializa-se e apreende os padrões gerais de uma cultura. Aprender ciências implica entrar em um mundo que se apresenta com uma linguagem própria, e tomar consciência das diferenças e das relações entre as linguagens da ciência e outras formas de falar e compreender o mundo (MORTIMER, 2000; VILLANI; NASCIMENTO, 2003).

Essa concepção de aprendizagem em ciências vai de encontro ao conceito de educação libertadora (e, como tal, essencialmente dialógica) em Paulo Freire, segundo o qual humanizar-se seria construir uma consciência crítica, uma consciência que problematiza causas. Nesse sentido, o trabalho do homem modifica a natureza e gera cultura e, humanizar-se seria apropriar-se da dimensão simbólica da linguagem. (FREIRE, 1992).

Da análise das produções escritas dos alunos, destacamos algumas implicações para o ensino, especialmente na EJA. Os professores têm uma tendência de esperar um assentimento total dos alunos em relação ao discurso da ciência escolar. Frequentemente, marcam como erro as tentativas "mal sucedidas" dos alunos de entrelaçarem seus modos de dizer com a voz da ciência escolar. De certa forma, isso cria no imaginário do estudante que, o bom aluno é aquele que é capaz de reproduzir fielmente os enunciados do professor.

Por outro lado, a imitação também tem um papel importante no processo de conceituação (FONTANA, 1996), pois possibilita ao estudante, com ajuda e apoio do professor, apropriar-se dos modos de dizer fixados culturalmente, ainda não dominados autonomamente.

Nos cinco textos analisados, bem como nos outros textos do total dos estudantes que responderam à primeira questão da avaliação final da sequência de ensino (Anexo 3), é evidente a ausência de questionamentos ao discurso escolar, 
nas produções escritas dos estudantes pesquisados neste trabalho. Atribuímos essa ausência ao modo como a questão foi redigida e pelo fato dos estudantes produzirem seus textos durante uma avaliação formal valendo nota, o que limita bastante qualquer relação de questionamento ao discurso científico escolar.

Em relação ao total de estudantes que realizaram a avaliação final (38 alunos), 45\% (17 alunos) responderam à questão discursiva de elaboração textual. Enquanto professores, consideramos relativamente baixo o percentual dos estudantes que escreveram o texto solicitado na avaliação final. Esse baixo índice não deve estar relacionado diretamente à frequência dos estudantes. Verificamos que 79\% (30 alunos) dos que realizaram a avaliação final apresentavam frequência considerada suficiente, e dos 17 estudantes que escreveram os textos na avaliação final, 71\% (12 alunos) eram frequentes nas aulas de Física. Por outro lado, um fator a ser considerado é que houve apenas uma avaliação formal aplicada três semanas após a sequência de ensino.

Em todo caso, pelo que nos propusemos analisar, é difícil afirmar algo sobre os estudantes que não responderam à questão discursiva da avaliação final. Talvez a negativa dos demais estudantes no momento e no contexto de uma avaliação formal se deva ao fato de não se considerarem capazes de dar uma resposta ao que lhes era solicitado pelo professor, seja por ainda não terem dominado o discurso científico escolar, seja pela própria dificuldade de lidar com o texto escrito. É comum percebermos um certo temor por parte dos estudantes frente a proposta de uma avaliação formal.

Contudo, destacamos que a busca das próprias palavras, pelos estudantes, ao produzirem seus enunciados, seja numa comunicação verbal oral ou escrita, revela seu grande esforço na tentativa de se apropriarem e internalizarem o discurso da ciência escolar. Essas marcas, nos modos de dizer dos estudantes, podem apontar não apenas "o quê" do discurso do professor foi apreendido, mas "como" o discurso do professor, que representa a voz da ciência escolar, foi ouvido.

\footnotetext{
NOTAS

${ }^{1}$ Estas produções escritas são representativas de um total de 17 estudantes que produziram o texto solicitado em resposta à primeira questão da avaliação final. No dia da avaliação estavam presentes 38 estudantes que realizaram a avaliação.

${ }^{2}$ As matrículas dos alunos são feitas no módulo que tenha vaga. Não há necessidade de se cursar os módulos I e II antes do Módulo III.

${ }^{3} \mathrm{Na}$ primeira parte dessa atividade, os alunos deveriam observar algumas tirinhas do Garfield, extraídas de Leituras de física: Mecânica para ler, fažer e pensar (GREF, 1998, p. 57), e explicarem as situações descritas nessas tirinhas por meio.

${ }^{4}$ Esse texto foi extraído de: APEC. Construindo Consciências - 8a série. São Paulo: Scipione, 2003.

${ }^{5}$ Extraído de GREF - Instituto de Física da USP, 1998.

${ }^{6}$ Extraído de APEC. Construindo Consciências, 8ª série. São Paulo: Scipione, 2003.
} 


\section{REFERÊNCIAS BIBLIOGRÁFICAS}

AGUIAR JR, O.; MENDONÇA, D. H.; SILVA, N. Análise do discurso em uma sala de aula de ciências: a postura do professor e a participação dos estudantes. In: Atas do VI Encontro Nacional de Pesquisa em Educação em Ciências. Florianópolis: UFSC, 2007.

AGUIAR JR, O.; MORTIMER, E. F.; SCOTT, P. As perguntas dos estudantes e seus desdobramentos no discurso da sala de aula de ciências. In: Atas do X Encontro de Pesquisa em Ensino de Física. Londrina: UEL, 2006.

APEC. Construindo Consciências - $8^{a}$ série. São Paulo: Scipione, 2003.

BAKHTIN, Mikhail. Estética da criação verbal. 2.ed. São Paulo: Martins Fontes, 1997.

BRONCKART, J.-P. Atividade de linguagem, textos e discursos: por um interacionismo sócio-discursivo. Tradução de Anna Rachel Machado, Péricles Cunha. São Paulo: EDUC, 1999.

COELHO, S. A. M.; EITERER, C. L. A didática na EJA: contribuições da epistemologia de Gaston Bachelard. In: SOARES, L.; GIOVANETTI, M. A. G. C.; GOMES, N. L. (Orgs.). Diálogos na educação de jovens e adultos. $2^{\mathrm{a}}$ ed. Belo Horizonte: Autêntica, 2006, p. 169-184.

DRIVER, R.; ASOKO, H.; LEACH, J.; MORTIMER, E. F.; SCOTT, P. Construindo conhecimento científico na sala de aula. Tradução de Eduardo Fleury Mortimer. Química Nova na Escola, n. 9, p. 31-40, 1999. FONTANA, R. A. C. Mediação pedagógica na sala de aula. Campinas, SP: Autores Associados, 1996. FREIRE, P. A importância do ato de ler: em três artigos que se complementam. $27^{a}$ ed. São Paulo: Cortez; Autores Associados, 1992.

GREF - Grupo de Reelaboração do Ensino de Física. Leituras de Física: Mecânica para ler, fazer e pensar. São Paulo: GREF - Instituto de Física da USP. Junho de 1998. Disponível em: http://axpfep1.if.usp.br/ gref/mec/mec2.pdf.

LIMA, M. E. C. C.; AGUIAR JR., O.; MARTINS, C. C. A formação de conceitos científicos: reflexões a partir da produção de uma coleção de livros didáticos. In: Atas do V Encontro Nacional de Pesquisa em Educação em Ciências. Bauru: UNESP, 2005.

MENDONÇA, D. H.; AGUIAR JR, O.; SILVA, N. Participação dos estudantes no discurso de uma sala de aula de ciências: tensão entre discurso dialógico e de autoridade. In: Atas do XI Encontro de Pesquisa em Ensino de Física. Curitiba: UFTPR, 2008.

MORTIMER, E. F. Linguagem e Formação de Conceitos no Ensino de Ciências. Belo Horizonte: Ed. UFMG, 2000.

MORTIMER, E. F.; MACHADO, A. H. Múltiplos Olhares sobre um episódio de ensino: Porque o gelo flutua na água? In: Anais do Encontro sobre Teoria e Pesquisa em Ensino de Ciências - Linguagem, Cultura e Cognição: reflexões para o ensino de ciências. Belo Horizonte, 1997.

MORTIMER, E. F.; SCOTT, P. Atividade discursiva nas salas de aula de ciências: uma ferramenta sociocultural para analisar e planejar o ensino. Investigações em Ensino de Ciências, v.7, n.3, p. 283-306, 2002. MORTIMER, E. F.; SCOTT, P. H. Meaning making in secondary science classrooms. Maidenhead, UK: Open University Press, 2003.

OLIVEIRA, M. K. Jovens e adultos como sujeitos de conhecimento e aprendizagem. Revista Brasileira de Educação, v. 12, p. 59-73, 1999.

OLIVEIRA, M. K. Ciclos de vida: algumas questões sobre a psicologia do adulto. Educação e Pesquisa, São Paulo, v. 30, n. 2, p. 211-229, maio/ago. 2004.

SILVA, N. S.; AGUIAR JR, O. O uso dos conceitos de elemento e substância por estudantes do ensino fundamental: uma perspectiva de análise sociocultural. Revista Brasileira de Pesquisa em Educação em Ciências. v. 8, n. 3, 2008.

SCOTT, P. S.; MORTIMER, E. F.; AGUIAR JR, O. The tension between authoritative and dialogic discourse: a fundamental characteristic of meaning making interactions in high school science lessons. Science Education, v. 90, n. 4, p. 605-631, 2006.

TOULMIN, S. Os usos dos argumentos. Tradução de Reinaldo Guarany. Martins Fontes: São Paulo, 2001. VILLANI, C. E. P..; NASCIMENTO, S. S do. A argumentação e o ensino de ciências: uma atividade experimental no laboratório didático de física do ensino médio. Investigações em Ensino de Ciências. Porto Alegre, v. 8, n.3, p.187-209, 2003.

VILLANI, A.; PACCA, J. L. A.; HOSOUME, Y. Concepção espontânea sobre movimento. Revista Brasileira de Ensino de Física. v. 7, n. 1, p. 37-45, 1985. 


\title{
ANEXOS
}

\author{
ANEXO 1: Atividade 1 \\ Lei da Inércia - A $1^{\text {a }}$ Lei de Newton
}

\section{Por que não percebemos a Terra se mover? ${ }^{5}$}

Galileu Galilei quase foi para a fogueira porque dizia que a Terra estava em movimento. E, realmente, este fato não parece algo razoável, porque não sentimos o movimento da Terra.

Se você estiver em um trem, em um barco ou no metrô, de olhos fechados, às vezes terá dificuldade de dizer se está ou não em movimento, mas quando olha para fora e vê a paisagem em movimento logo se dá conta de que está se deslocando.

$\mathrm{Na}$ verdade, se o movimento do trem, barco ou metrô for uniforme, ou seja, sua velocidade se mantiver sempre a mesma, em linha reta e se não houver trepidações e vibrações, tudo se passa como se estivéssemos parados. Se não olharmos para fora e não ouvirmos o som dos motores é impossível saber se estamos em movimento ou não.

Galileu percebeu que esta era a explicação para o fato de não sentirmos o movimento da Terra. Mas isso tem consequências ainda mais fortes: significa que os movimentos são relativos.

O que quer dizer isso? Uma pessoa sentada no outro banco do trem está parada em relação a você que está lá dentro, mas está em movimento do ponto de vista de quem está fora do trem. Qual é ponto de vista mais correto? O seu, ou o da pessoa que vê tudo de fora? A resposta é: nenhum! Afinal, quem estivesse "de fora" da Terra também veria a pessoa "parada" fora do trem em movimento.

Todos que estejam em movimento uniforme em relação aos outros podem dizer que seu ponto de vista é o correto. A isso chamamos de referencial.

Tudo isso está intimamente ligado à Primeira Lei de Newton, também conhecida como Lei da Inércia.

"Todo corpo continua em seu estado de repouso ou de movimento em uma linha reta, a menos que ele seja forçado a mudar aquele estado por forças imprimidas a ele."

Dê mais uma olhada nessa lei. O estado de repouso de uma bola no chão do trem em movimento uniforme equivale ao estado de movimento de quem vê esta mesma bola de fora do trem.

Para tirá-la do repouso alguém dentro do trem pode dar um cutucão na bola. Quem está de fora verá que a bola, que estava em movimento constante junto com o trem, mudar seu movimento, ou seja, alterar o seu estado de movimento.

E o que acontece se o trem brecar de repente? Bem, neste caso sim podemos sentir o efeito. Parece que estamos sendo jogados para frente. Agora o trem deixa de ser um referencial equivalente aos outros, porque ele mesmo está variando seu movimento.

Nestas condições, uma bola no piso do trem pareceria iniciar um movimento para frente. $\mathrm{Na}$ verdade, quem está de fora terá condições de dizer que o trem está parando e a bola simplesmente tendeu a continuar o movimento que possuía antes. O mesmo aconteceria a todos nós se a Terra freasse de repente o seu movimento: nós nos sentiríamos sendo "jogados", e isso certamente causaria grandes catástrofes, dependendo da intensidade desta "freada".

Se a Terra se move, e também os outros planetas, há algo que pode ser considerado realmente "em repouso"? A resposta é não! Mesmos as estrelas, como o Sol, estão em movimento quase uniforme uma em relação a todas as outras. Portanto, a velocidade de algo no espaço sempre tem que ser indicada em relação a alguma outra coisa, porque não há nada que possa ser considerado realmente "parado". 


\section{Problemas}

1) O que acontece aos passageiros quando um ônibus dá uma freada brusca? Como você explica este fato?

2) Quando o ônibus dá uma arrancada repentina, o que ocorre? Explique baseado nas discussões do texto anterior.

3) Por que é tão perigoso saltar de um ônibus em movimento?

4) Uma bolinha de aço está apoiada sobre um carrinho que possui uma superfície muito lisa. Quando uma pessoa puxar o carrinho para a direita, a bolinha irá:

A) cair à direita do ponto A.

B) cair sobre o ponto $\mathrm{A}$.

C) cair à esquerda do ponto A.

D) cair em local imprevisível

JUSTIFIQUE sua resposta.

5) Observe a figura ao lado:

Daniel está andando de skate em uma pista horizontal. No instante (1), ele lança uma bola. A bola sobe alguns metros e cai, enquanto Daniel continua a se mover em trajetória retilínea, com velocidade constante. No instante

(2) a bola retorna à mesma altura em que foi lançada.

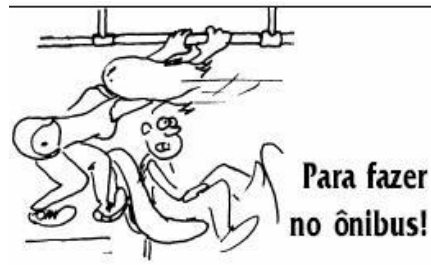

DESCREVA como é a trajetória da bola do ponto de vista de Daniel e INDIQUE em que ponto ela irá cair.

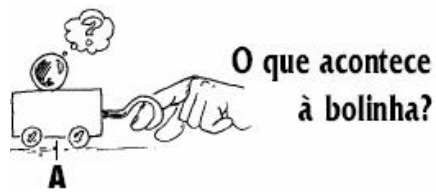

\section{ANEXO 2: Atividade 2}

1) Garfield e Jon são dois personagens do desenho animado criado por Jim Davis. Garfield é um gatinho gordo e muito conhecido por sua esperteza.

Ao lado estão alguns quadrinhos de Jim Davis extraídos da Folha de São Paulo e da revista "Garfield na Maior". Observe esses quadrinhos e responda às questões.

A) Qual é a primeira lei da Física a que Garfield se refere no quadrinho I para justificar-se com Jon? O que diz essa lei?

B) Como a primeira lei da Física explica a situação representada no quadrinho II?

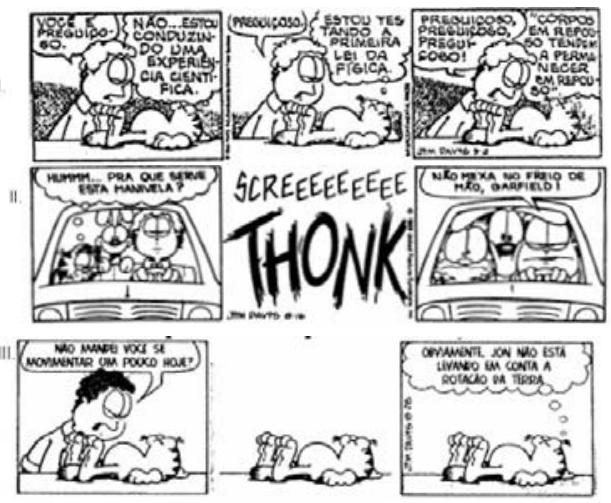

C) Observe o quadrinho III. Considerando-se a ordem de Jon, EXPLIQUE por que a justificativa de Garfield não é válida. 
2) Leia o texto abaixo e discuta com seus colegas as questões que o seguem. ${ }^{6}$

\section{Preconceito muito pra frente}

Toda hora vejo, em jornais, revistas, televisão, e na rua, pessoas cada vez "livres" de preconceitos e (...). E no entanto todas estão convencidas de que a Terra gira em torno do Sol. Por que? Pergunte a elas e elas responderão: "vê, Galileu provou isso a muito tempo". Mas provou pra quem? Pode ser que tenha provado pros cientistas. O homem comum, e mesmo nós, os pejorativamente chamados intelectuais, aceitamos e pronto. Sem pensar. Preconceituosamente. Como antes de Galileu acreditávamos que o Sol girava em torno da Terra. Mas, entre Galileu - de cujas "provas" nunca tomamos conhecimento nem sabemos dizer quais são - e a realidade, que literalmente sala (gira) a nossos olhos, temos que acreditar é em nossos olhos. Nossos olhos vêem, com absoluta certeza, que o Sol nasce ali (a leste) e morre do outro lado (a oeste), girando em torno de uma Terra absolutamente parada (terremotos à parte), sobre a qual caminhamos sem sentir o menor movimento. Pra mim o Sol gira em torno da Terra e estamos conversados.

(FERNANDES, Millôr. Jornal do Brasil, p.11, 26/01/1990)

A) De acordo com o texto, quando é que agimos preconceituosamente?

B) Agora que você já sabe quais foram os argumentos de Galileu (Movimento Relativo e Lei da Inércia), escreva uma carta a Millôr, tentando convencê-lo de que é possível admitir a ideia de que a Terra se move.

\section{ANEXO 3: Avaliação final (primeira questão)}

1) Durante muito tempo acreditou-se que a Terra estivesse parada ocupando um lugar de destaque no centro do Universo. Essa ideia perdurou durante quase 2 mil anos, da Grécia Antiga até os tempos do físico Galileu. Convencido de que a Terra se movia, Galileu rompeu com a antiga ideia tentando mostrar que é possível admitir que a Terra se move.

Escreva um pequeno texto argumentando a favor da hipótese de Galileu de que a Terra se move. O texto deve conter as seguintes palavras: Lei da Inércia, movimento relativo, velocidade constante. 
